\title{
A IMPORTÂNCIA DA ÁGUA DE REUSO NA AGRICULTURA E AS CONSIDERAÇÕES DA VIGILÂNCIA SANITÁRIA SOBRE A PRÁTICA SUSTENTÁVEL
}

\author{
Lucas dos Santos Silva ${ }^{1}$ \\ Illielda Aryanny da Silva Nascimento ${ }^{2}$ \\ Mikaila Romão de Carvalho ${ }^{3}$ \\ José Vytor Silva Neto ${ }^{4}$ \\ Erivelton André da Silva
}

THE IMPORTANCE OF WATER FOR REUSE IN AGRICULTURE AND THE CONSIDERATION'S OF HEALTH SURVEILLANCE ON SUSTAINABLE PRACTICE

\begin{abstract}
RESUMO: A água é um recurso natural escasso e fundamental para a sobrevivência humana, essa realidade se torna ainda mais grave quando analisamos que a quantidade de água potável e disponível para consumo é muito pequena comparada à quantidade de água salgada que não pode ser ingerida sem tratamentos químicos rigorosos. Logicamente, a grande quantidade de pessoas que existem no mundo, contribui para que o consumo da água seja cada vez maior, porém as atividades realizadas pelo agronegócio representam cerca de $70 \%$ de todo esse consumo. Sendo assim, é importante que se desenvolvam saídas para que esse consumo diminua e seja racionado. O objetivo geral do presente trabalho é demonstrar como a utilização de água de reuso pode ser a chave para uma utilização hídrica mais sustentável. A reutilização da água inviabiliza o uso descriminado desse recurso, representa uma grande economia para o setor agricultor e favorece a melhor distribuição desse recurso.
\end{abstract}

Palavras-Chave: Água. Água de reuso. Agricultura. Sustentabilidade. Vigilância Sanitária.

ABSTRACT: Water is a scarce and fundamental natural resource for human survival, this reality becomes even more serious when we analyze that the amount of drinking water available for consumption is very small compared to the amount of salt water that cannot be ingested without chemical treatments. strict. Logically, the large number of people that exist in the world, contributes to the increasing consumption of water, however the activities carried out by

${ }^{1}$ Bacharel em Biomedicina pela Faculdade Maurício de Nassau/ CARUARU-PE e especialista em Saúde Pública pela ASCES-UNITA.E-mail: lucas.santos.biomed@gmail.com.

${ }^{2}$ Bacharela em Fisioterapia pela Faculdade ASCES-UNITA, Especialista em fisioterapia Neurofuncional pela Faculdade Redentor e Residente em Atenção Básica/ Saúde da Família pela Faculdade ASCESUNITA.E-mail: illieldan@gmail.com.

${ }^{3}$ Bacharela em Odontologia pela Faculdade ASCES-UNITA e especialista em Saúde Pública pela ASCESUNITA.E-mail: mikailacarvalhor23@gmail.com.

4 Bacharel em Biomedicina pela Faculdade Maurício de Nassau/ Caruaru-PE e especialista em Hematologia pela ASCES-UNITA.E-mail: vytornetor23@gmail.com.

5 Bacharel em Educação Física pela Universidade Federal de Pernambuco- UFPE. E-mail: erivelton.andre@hotmail.com. 
agribusiness represent about $70 \%$ of all this consumption. Therefore, it is important that outlets are developed so that consumption decreases and is rationed. The general objective of the present work is to demonstrate how the use of reuse water can be the key to a more sustainable water use. The reuse of water prevents the discriminated use of this resource, represents a great saving for the agricultural sector and favors the better distribution of this resource.

Keywords: Water. Reuse water. Agriculture. Sustainability. Health Surveillance.

\section{INTRODUÇÃO}

A escassez da água é um dos problemas mais comentados quando o assunto é sustentabilidade e o futuro do planeta Terra junto da espécie humana, porém, o desenvolvimento de ações efetivas que favoreçam a economia dos recursos hídricos ainda é recente e um tanto quanto insuficiente visto que a problemática segue crescendo.

Inicialmente, é importante salientar que a água possui uma série de utilidades que vão bem além do consumo. Os recursos hídricos são usados em quase todos os setores da economia e ambientes sociais, como empresas, comércios, fabricações, casas, escolas, dentre outros. Dessa forma, muitas vezes a água utilizada ainda se encontra com vida útil, porém é descartada mesmo assim.

Essa realidade se deve ao fato de que a sustentabilidade, na maioria das vezes, não é ensinada nas escolas ou faz parte de tradições familiares, como deveria ocorrer. Sendo assim, uma boa parte da população não desenvolve a consciência de que suas atitudes causam grandes impactos para a saúde do planeta e colocam em risco o bem estar das próximas gerações.

A água de reuso, em uma definição mais ampla, é exatamente a água que já é utilizada, mas que ainda possui vida útil para participar de determinados processos que não exigem que a qualidade da água seja tão pura. Logo, essa água pode ser coletada, armazenada e reutilizada da maneira correta, contribuindo para a diminuição do uso dos recursos hídricos, favorecendo a economia e a sustentabilidade.

O objetivo geral do presente trabalho é demonstrar a importância da água de reuso para o agronegócio e como essa ação pode favorecer a economia e a sustentabilidade desse setor, bem como demonstrar quais são as considerações da vigilância sanitária sobre a prática. Os objetivos específicos consistem em pontuar a sustentabilidade e sua importância em um contexto atual, discorrer sobre os setores que compreendem ao agronegócio e colocar a água de reuso como uma saída sustável e econômica.

A metodologia escolhida para o desenvolvimento desse trabalho é descritiva e qualitativa e faz parte da classe das pesquisas bibliográficas. Bem como se apresentam todos os estudos caracterizados como revisões, este estudo foi elaborado através de uma pesquisa bibliográfica 
sobre o tema. Realizando a leitura, seleção e compreensão dos materiais acadêmicos encontrados nas plataformas como Scientific Electronic Library Oline (SCIELO), Literatura Latinoamericana em Ciências da Saúde (LILACS) e Public Medine or Publisher Medine (PUBMED), nos idiomas português e inglês.

\section{REFERENCIAL TEÓRICO}

\section{Sustentabilidade e recursos hídricos}

Dias (20II) afirma que a sustentabilidade pode ser definida como uma ideologia ambientalmente correta, ou seja, se trata de um conjunto de idéias, atitudes e campanhas que são realizadas e alteradas em prol da proteção e reparação do meio ambiente. Sempre incluindo a fauna e a flora, isso porque ideologias sustentáveis, de fato, visam melhorar a qualidade de vida de animais, vegetação, rios, mares, dentre outros.

A importância da sustentabilidade vai além da adoção de um conjunto de ações politicamente corretas, se trata na verdade da preservação do que ainda resta da natureza depois de milhares de anos consumindo seus recursos sem o mínimo de preocupação com o futuro. Para que ainda possa ser feito uso de tais recursos no futuro, é preciso que os mesmos sejam protegidos e conservados de forma sustentável (DIAS, 20II).

Para que uma empresa possa ser de fato considerada sustentável, é preciso que a mesma seja detentora de selos e certificações de sustentabilidade. A norma ISO I40or visa fazer com que as empresas sejam mais do que ecologicamente corretas e sim que possuam uma área de gestão ambiental. Demonstrando assim que as mesmas podem crescer e evoluir no mercado, mesmo sendo sustentáveis (MARTINS, 2014).

Segundo Barbieri et. al (2010) as indústrias correspondem ao setor que mais faz uso dos recursos naturais e desgasta o meio ambiente de forma geral, enquanto a agropecuária é o setor que mais gasta água. Porém, o consumo proveniente de outras fontes também é extremamente significativo e caso seja reduzido, trás benefícios para o meio ambiente.

Quando citamos essas outras fontes podemos utilizar como exemplo os sistemas de irrigamento das casas, clubes e condomínios e sistemas de ar condicionado, em ambos os casos o consumo de água é muito inferior ao utilizado pelas indústrias e pela agropecuária. Mas, ainda sim consomem muita água e por longos períodos de tempo (MONTE, ALBUQUERQUE, 2010).

A água é o recurso natural mais importante para a continuação das espécies animais e vegetais na Terra, isso porque é necessária para a sobrevivência de quase todos os seres vivos. Ainda segundo Monte; Albuquerque (2010) os humanos e algumas outras espécies de animais necessitam de água doce e potável para a manutenção de sua saúde, tornando o desperdiço de 
água uma questão muito constante nas últimas décadas.

A água é considerada um recurso natural renovável, isso porque as chuvas possuem como uma de suas funções fazer a reposição dessa água. Porém, existe uma grande diferença entre a água em sua totalidade e a água disponível para uso e consumo humano. Isso porque, a água precisa atender a alguns critérios de qualidade que se referem a sua composição química para que possa ser considerada potável. Acredita-se que existam mais de 50 componentes químicos na água antes que a mesma seja tratada, os recursos hídricos fazem uso de processos químicos, físicos e biológicos para diluir tais componentes que podem prejudicar a saúde humana (DA SILVA, 2013).

Como bem explica Tundisi (20II) à água é encontrada na natureza nos estados líquidos, sólidos e gasosos. No que se refere a sua localização, essa água pode ser subterrânea, atmosférica ou superficial. Os recursos hídricos disponíveis e utilizados no Brasil conseguem ter acesso às águas que se encontram superficiais ou subterrâneas, que são usadas para diversas ações necessárias à sociedade moderna como a geração de energia elétrica, abastecimento residencial e industrial, dentre outras.

O primeiro requisito para que a água seja considerada própria para consumo após tratamento, é que a mesma seja doce. Apenas 3\% da água encontrada na Terra é doce, os outros $97 \%$ são compostos por água salgada. Além disso, 2,5\% dessa água doce se encontram nas geleiras polares e apenas $0,5 \%$ em aquíferos. O Brasil, enquanto país de grande extensão territorial, possuí I2\% da água doce disponível em todo o mundo. Porém, a distribuição dessa água é extremamente problemática devido a sua irregularidade (TUNDISI, 20II).

A desigualdade na distribuição hídrica brasileira se dá devido ao fato de que a disponibilidade de águas subterrâneas não é constante em toda a extensão territorial do Brasil. As regiões Sul e Sudeste do país, juntamente com a Amazônia, contam com uma quantidade muito maior de água do que toda a região Nordeste (MARENGO et. al, 2015). Sendo assim, o desenvolvimento de medidas sustentáveis que reduzam o consumo de água são extremamente bem vindas, uma dessas medidas irá ser apresentada no tópico a seguir.

\section{Água de Reuso e Reaproveitamento}

Segundo dados divulgados pela Organização das Nações Unidas (ONU), até o ano de 2017, o planeta Terra era o lar de 7,59 bilhões de pessoas, número alarmante quando comparado ao de algumas décadas atrás. Outro fator que deve ser mencionado é a expectativa de vida geral, incluindo a dos brasileiros. Se nos séculos passados era comum que uma pessoa vivesse até cerca de 50 ou 60 anos, hoje essa média beira os 80 anos de vida (BOFF, 2017). 
A superpopulação e a ausência de metodologias e ação sustentáveis resultaram na degradação contínua do meio ambiente e de todos os ecossistemas. Essa realidade pode ser visualizada quando analisamos as alterações no clima, a qualidade do ar, a saúde do solo e a expectativa de vida das espécies não humanas marinhas e terrestres (TUNDISI, 20II).

Dessa forma, se iniciaram uma série de campanhas e iniciativas que visam diminuir os impactos humanos na natureza, principalmente no que diz respeito ao esgotamento dos recursos naturais, mais especificamente a água. Porém, ainda existe uma grande dificuldade no acesso a informação de qualidade e derivadas de fonte seguras sobre ecologia e iniciativas sustentáveis que podem ser realizadas diariamente e que tragam impactos positivos para o meio ambiente em longo prazo.

Como já supracitado, a água é fundamental para a sobrevivência da vida na Terra, não apenas a humana como também a de quase todos os seres que habitam o planeta. Logo, é importante que as metodologias de ação sustentáveis sejam apresentadas e incentivadas em escolas e demais instituições de ensino, mas que também chegue às casas e faça parte da cultura familiar da sociedade.

Essas iniciativas sustentáveis são variadas, bem como também os níveis de dificuldade de sua aplicabilidade, também são variadas. Mas, no que se refere aos recursos hídricos que é o foco deste trabalho, podemos colocar o reuso e o reaproveitamento da água como ações eficientes para a diminuição do uso deste recurso natural.

Como bem cita Silva (2012), outros setores fazem uso dos recursos hídricos com muito mais frequência e em maiores quantidades do que os lares e demais instituições, porém, economias pequenas tendem a causar impactos significativos no futuro, e levando em consideração o estado de degradação em que nos encontramos é possível afirmar que esses esforços pequenos se tornaram grandes em um futuro próximo.

Em um momento inicial, é preciso que se compreendam as diferenças entre o reuso e o reaproveitamento da água, que existem mesmo que o objetivo final de ambos os processos sejam apenas um: reutilizar a água e evitar desperdícios e atrasar o esgotamento dos recursos hídricos (SILVA, 2012).

Em linhas gerais, Silva; Santana (2014) nos explica que o reaproveitamento da água está mais associado às águas pluviais, ou seja, a água da chuva. Logo, o reaproveitamento da água se trata da coleta, armazenamento e reutilização da água da chuva. Essa água da chuva pode ser considerada um desperdício, visto que apesar de não poder ser utilizada para fins nobres, tem muitas utilidades operacionais como lavar carros, calçadas, limpar objetos do quintal, dentre outras coisas. 
Enquanto isso, o reuso da água se aplica a todos os recursos hídricos que já foram utilizados para fins nobres como banho, lavar louça, lavar alimentos, dentre outras ações. O reuso da água consiste em coletar a mesma e utiliza-la para outras funções que não exigem uma água tão pura, como dar descarga, molhar a grama e as plantas, dentre outras ações (SILVA; SANTANA, 2014).

Ambas as ações, o reuso e o reaproveitamento da água, são iniciativas sustentáveis e contribuem muito para o não esgotamento dos recursos hídricos disponíveis no planeta Terra. Podem ser executadas em ambientes familiares ou demais instituições de convivência social como lojas, escolas, organizações, e outros.

Segundo Santos et. al (2014) existem sistemas que podem ser desenvolvidos e aplicados que viabilizam a coleta da água para o reuso ou reaproveitamento. Como a construção de calhas interligadas a reservatórios onde a água da chuva é reaproveitada, ou até mesmo coisas mais simples como um balde no chuveiro que colete a água que sobra do banho e a mesma seja usada para dar descarga.

\section{Sistemas de Reuso e Reaproveitamento de água}

Além de todas as utilidades da água já citadas anteriormente, o ar condicionado, aparelho amplamente utilizado no Brasil e em diversos países do mundo, precisa de recursos hídricos para funcionar. Para Bertolasi (2010) diversas funções realizadas pelo ar condicionado dependem da água para serem executadas e a falta da mesma compromete o funcionamento do aparelho causando diversos tipos de danos.

Segundo Campos et. al(2010) o Brasil é um país tropical onde o clima costuma ser quente durante boa parte do ano e na maior parte dos Estados do país, aliado a esse fato podemos citar que a urbanização das cidades elevaram o número de prédios construídos e o tamanho dos mesmos. Tal realidade faz com que o ar tenha mais dificuldade para circular e a sensação térmica seja elevada, aumentando a quantidade de pessoas que fazem uso de aparelhos de ar condicionado para controlarem a temperatura de seus lares, empresas e comércios.

Porém, os aparelhos de ar condicionado fazem uso da água de forma direta em dois momentos: através da energia elétrica que usam e da água que necessitam para funcionar. Quanto maior a quantidade de aparelhos funcionando, maior segue sendo a quantidade de água utilizada nesse processo fazendo com que se torne extremamente importante um sistema que faça reuso e reaproveitamento desses recursos hídricos. Para Carvalho et al (2012) a água proveniente da retirada da umidade do ar e condensada pelo ar condicionado, pode ser facilmente usada para diversas funções como a irrigação de áreas verdes, sistema de esgoto, limpeza de ambientes 
externos, dentre outras.

Para que esse reaproveitamento aconteça é preciso que se instale um sistema de coleta e armazenamento da água proveniente dos aparelhos de ar condicionado, de modo que acha a disposição da mesma para uso em outras funções futuras. De forma que a água potável e limpa, não seja utilizada para funções menos importantes.

Segundo Souza (2010) a definição de condicionamento de ar consiste em um sistema que melhora a qualidade e controla a temperatura do ar de espaços fechados até determinados tamanhos. Porém, os benefícios do condicionamento de ar não estão ligados apenas à temperatura do ambiente, mas também a umidade, limpeza e circulação do ar.

Esse ar que passa pelo tratamento já supracitado é chamado de ar condicionado e os aparelhos utilizados para cumprirem essa função são os ares condicionados. A climatização por si só não poder ser definida como condicionamento de ar, visto que ambas possuem funções e apresentam desempenho diferente (RUPP, 2017).

Apesar da função do ar condicionado estar muito ligada a baixa da temperatura ambiente para que haja um maior conforto, muitos aparelhos são utilizados de forma vital. Hospitais, empresas e determinados tipos de indústrias necessitam que o ar esteja frio para continuarem funcionando. Isso porque caso a temperatura ambiente esteja beirando os $35^{\circ}$ ou até mesmo $40^{\circ}$ como ocorre em diversas regiões do país, a validade de remédios pode ser comprometida, matérias primas e produtos podem se estragar, alimentos, dentre outros.

O primeiro ponto que precisa ser pontuado é que água reaproveitada dos ares condicionados não é, de maneira alguma, potável. Isso é, mesmo que seja armazenada e tratada da forma correta ainda não atenderia todos os requisitos de qualidade, sendo também um processo caro e não benéfico pela quantidade de água e a forma como a mesma é produzida.

Porém, existem muitas funções que executamos no dia a dia que não precisam de água potável, mas que usamos água corrente quando poderíamos usar água reaproveitada a fim de economizar esse recuso tão precioso. A água que cai do aparelho de ar condicionado, na ausência de um sistema de reuso, vai direto para o esgoto ou escoa pelo solo, sendo completamente desperdiçada.

Segundo Rigotti (2015) essa água que cai do aparelho de ar condicionado muitas vezes escorre por meio de pingos, essa realidade faz com que se desenvolva a impressão de que pouca água está sendo desperdiçada. Porém, existem ambientes onde o ar condicionado fica ligado por longos períodos, nesses casos a quantidade de água que foi rejeitada ao longo de 24 horas pode chegar a litros.

A parte do ar condicionado responsável pelo controle do fluxo de água obtido através da 
umidade do ar é o dreno, componente que muitas vezes apresenta defeito quando não há manutenção periódica e pode prejudicar o ar condicionado de muitas formas. A drenagem dos aparelhos de ar condicionada por ser feita por meio de mangueiras (nos casos de ar condicionado de janela) ou por meio de tubulações (ar condicionado o tipo split), e ambos os sistemas são capazes de direcionar e armazenar essa água para reuso. O processo de aplicação de um sistema de reuso da água desperdiçada pelo aparelho de ar condicionado é extremamente simples, mas para que funcione de maneira correta todo o aparelho deve ter sido instalado por um profissional capacitado.

A maioria dos sistemas de reuso e reaproveitamento de água seguem a mesma base, necessitam da idealização e produção de um sistema que seja capaz de executar as funções necessárias, sendo elas a coleta, o armazenamento seguro e disponibilização para o reuso e reaproveitamento da mesma. Da forma como ocorre no setor de agricultura e que será descrito neste trabalho.

Como bem coloca Souza (2010) o estilo de vida moderno nas grandes cidades influenciou muito no consumo dos recursos hídricos, o ar condicionado para uso residencial é uma das maiores representações dessa realidade. Visto que é um sistema que necessita da utilização de água, mas não faz o uso completo da mesma, abrindo espaço para que a mesma seja facilmente reutilizada caso haja consciência ambiental para tal.

Dessa forma, esse sistema apresentado acima, é um exemplo de um sistema idealizado, produzido e utilizado para o reuso e reaproveitamento da água que deriva dos sistemas de ar condicionado, sistema esse utilizado em ambiente urbano e rural. Os próximos tópicos do presente trabalho irão discorrer sobre o papel do reuso da água no agronegócio e exemplificar o sistema utilizado nesse meio.

\section{Água de Reuso e o manejo de alimentos}

Como bem coloca Marengo (2015) o agronegócio, de maneira geral, o setor que mais consome os recursos hídricos no Brasil. Tal realidade contribuiu muito para o fortalecimento das ideologias que definem a sustentabilidade residencial como desnecessária, já que se estaria economizando água apenas para que o agronegócio pudesse usar com menos culpa.

Porém, tal ideia é errada e extremamente ultrapassada. E dois motivos podem ser colocados para comprovar essa afirmação: o primeiro deles é que já é de conhecimento público que a sustentabilidade a nível mundial é um processo, ou seja, ações realizadas agora surtirão impacto real para a saúde do planeta apenas daqui a boas décadas, mas, com certeza terão sua utilidade cumprida. 
Já o segundo motivo está associado à sustentabilidade empresarial e industrial, ou seja, as novas iniciativas sociais de mercado que colocam o meio ambiente como fator extremamente importante na busca pela maximização do faturamento em um mundo completamente capitalista. Isso é, o agronegócio também está no início de um processo de conscientização e busca pela redução dos seus impactos para o meio ambiente, principalmente no que se refere aos recursos hídricos.

Sendo assim, várias iniciativas já foram idealizadas, desenvolvidas e estão sendo colocadas em prática nesse setor, bem como em tantos outros. Rocha et. al (2010) alerta que o agronegócio é responsável pelo uso de 70\% de todos os recursos hídricos do mundo, e boa parte disso se deve ao uso indiscriminado e a total ausência de conscientização ambiental que marca o histórico desse setor.

No que se refere aos recursos hídricos, De Brito et. al (2012) coloca a reutilização da água como uma saída extremamente viável, isso porque muitos são os processos que exigem a utilização de água, porém, não inviabilizam a mesma para ser utilizada em fins menos nobres, como a irrigação de plantios, lavagem de ambientes externos e maquinários, dentre outras funções.

Ou seja, a reutilização da água utilizada na agricultura não é capaz de fazer com que os processos realizados utilizem menos água, porém, fazem com que essa água que já foi utilizada não seja desperdiçada, bem como evita que uma grande quantidade de uma água nova seja utilizada para funções que não exigem uma purificação elevada (DE BRITO et. al, 2012).

De maneira mais prática, Dantas et. al (2014) coloca que os sistemas que viabilizam a reutilização da água são variados e se diferem no nível de dificuldade e investimento necessário, porém, tais escolhas dependem diretamente do tipo de serviço agropecuário realizado nessa região. Isso porque quanto maiores forem os empreendimentos e obrigações diárias, mais sofisticadas deve ser o sistema de coleta, armazenamento e reuso de água.

No caso de empreendimentos que visam reutilizar a água de maquinários e ações específicas, é possível que isso seja possível apenas através de bombas de água e baldes, porém, no caso de necessidade do reuso de água em setores internos é preciso que se projete um sistema que otimize essa coleta e armazene a água de forma correta, evitando assim proliferação de doenças, e o comprometimento ainda maior da qualidade da mesma (DANTAS et. al, 2014).

São muitos os sistemas utilizados no agronegócio para reuso e reaproveitamento da água, mas mesmo assim, ainda não são suficientes para suprir o intenso uso da mesma pelo setor. Porém, é importante que toda evolução seja amplamente pontuada e que sirva de exemplo.

Torres et. al (2018) nos explica o funcionamento de um desses sistemas de reuso e 
reaproveitamento da água. Visto que o desperdício de água não ocorre apenas no campo, mas também nas casas dos fazendeiros, um dos sistemas mais famosos e úteis de reaproveitamento $e$ reuso de água faz exatamente essa ligação.

Caixas de reservatórios de água são acopladas por meio de canos as pias, máquinas de lavar e chuveiros das casas, logo, a água que sobra desses processos vai direto para esses reservatórios e depois passa por um processo de limpeza básica que conta com pedras, cascalho e os humos das minhocas (TORRES et. al. 2018).

Após esse processo, a água já se encontra pronta para ser utilizada no campo e cumprir funções menos nobres, como compor o sistema de gotejamento para irrigação das plantações, lavagem de materiais, dentre outras (TORRES et. al. 2018).

A irrigação é uma das práticas que faz mais uso dos recursos hídricos de forma continua e por isso é um dos maiores focos de pesquisas visando à diminuição dos impactos causados pela prática. Rigo et. al (2014) defende a coleta, o tratamento e o reuso das águas do esgoto para a irrigação no agronegócio.

Apesar de inicialmente parecer uma ideia absurda, é completamente compreensível quando analisada do ponto de vista lógico e químico. Isso porque, a água que deriva dos esgotos é muito contaminada por impurezas nocivas aos seres humanos, porém, também conta com uma infinidade de nutrientes que podem ser úteis em determinados pontos de irrigação (RIGO, et, al, 2014).

A água é coletada do esgoto através de um sistema desenvolvido para cumprir esse trabalho, depois é submetida por um longo processo de desintoxicação e nela são adicionados químicos que podem minimizar os efeitos das toxinas presentes no esgoto, mantendo a ação dos nutrientes, e após esse processo é importante que o lugar onde a água de irrigação for usada, seja escolhido de forma consciente visto que não são todos os tipos de plantação recomendados para o uso desse tipo de água de reuso (RIGO, et, al, 2014).

Apesar de o reuso de água ser muito recomendado, considerando o quão é importante o seu racionamento, não é possível, por exemplo, reutiliza-la em qualquer situação. Quando o assunto é alimentos, no caso de plantio até é possível utilizar. É possível utilizar a água da chuva para limpar o material e equipamentos utilizados, porém, no alimento propriamente dito não é possível, pois o risco de contaminação é muito grande. Sobre o tema, o Centro de Vigilância Sanitária coloca que:

A oferta de água em quantidade e qualidade adequada é fator imprescindível para a prevenção de riscos à saúde e melhoria da qualidade de vida da população. Por este motivo, o setor saúde assumiu historicamente papel ativo na vigilância da qualidade da água para consumo humano. Esta atribuição 
adquire alto grau de complexidade em um estado como São Paulo, que conta com 4I,2 milhões de habitantes, taxa de urbanização de $95,9 \%$ e o maior parque industrial do país (CENTRO DE VIGILÂNCIA SANITÁRIA, 2015).

O Conselho Nacional do Meio Ambiente (CONAMA) regula a qualidade da água de reuso e a sua utilização direta ou indiretamente na irrigação de alimentos, principalmente aqueles que são consumidos diretamente após a produção, ou seja, não passam por nenhum tipo de transformação industrial, por isso, é importante estar ciente de todas as resoluções e documentos oficiais.

\section{CONCLUSÃO}

Mediante os conhecimentos obtidos para que fosse viabilizada a produção do presente trabalho acadêmico, foi possível perceber o quão grave é a problemática da saúde do planeta, especialmente no que se refere aos recursos hídricos.

Apesar de as tendências mundiais estarem passando por um processo de alteração, onde o consumo passa a ser repensado em busca de uma maior conscientização dos impactos que cada ação causa no meio ambiente, ainda existe muito caminho a ser percorrido para que a raça humana possa ser considerada sustentável.

Mesmo que as atividades agrícolas, e o agronegócio de maneira geral, sejam os maiores responsáveis pelo consumo desenfreado de água no mundo, ainda é extremamente necessário e valioso que as famílias e os lares adotem iniciativas sustentáveis, mesmo que essa pareça uma ação inútil.

A água de reuso e o reaproveitamento da água são saídas eficazes e menos complicadas para contribuir para a saúde do meio ambiente de forma positiva, ainda mais quando essa prática é colocada no contexto da agricultura que compreende um setor que faz uso indiscriminado dos recursos hídricos.

\section{REFERÊNCIAS}

BARBIERI, José Carlos et al. Inovação e sustentabilidade: novos modelos e proposições. RAERevista de Administração de Empresas, v. 50, n. 2, p. 146-154, 2010.

BOFF, Leonardo. Sustentabilidade: o que é-o que não é. Editora Vozes Limitada, 2017.

CUNHA, Ananda Helena Nunes et al. O reúso de água no Brasil: a importância da reutilização de água no país. Enciclopédia biosfera. Centro Científico Conhecer-Goiânia, v. 7, n. 13, p. 1225I248, 2011.

DA SILVA, Mayssa Alves; DE SANTANA, Claudemir Gomes. REUSO DE ÁGUA: 
possibilidades de redução do desperdício nas atividades domésticas. 2014.

DA SILVA, Vicente de PR et al. Uma medida de sustentabilidade ambiental: Pegada hídrica. Revista Brasileira de Engenharia Agricola e Ambiental-Agriambi, v. 17, n. I, 2013.

DANTAS, Iasmine Louise de Almeida et al. Viabilidade do uso de água residuária tratada na irrigação da cultura do rabanete (Raphanussativus L.). Revista Ambiente \& Água, v. 9, n. I, p. I09-II7, 2014.

DE BRITO, Ramilos Rodrigues; GOMES, Edilson Ramos; LUDWIG, Rafael. Uso da água na irrigação. Periódico Eletrônico Fórum Ambiental da Alta Paulista, v. 8, n. 2, 2012.

DE OLIVEIRA CAMPOS, VAlériANAgy; PAULA FRACALANZA, A. N. A. Governança das águas no Brasil: conflitos pela apropriação da água e a busca da integração como consenso. Ambiente \& sociedade, v. 13, n. 2, p. 365-382, 2010.

DIAS, Reinaldo. Gestão ambiental: responsabilidade social e sustentabilidade. In: Gestão ambiental: responsabilidade social e sustentabilidade. 2011.

JACOBI, Pedro Roberto; CIBIM, Juliana; LEÃO, Renata de Souza. Crise hídrica na Macrometrópole Paulista e respostas da sociedade civil. Estudos avançados, v. 29, n. 84, p. 27-42, 2015 .

MARENGO, José A. et al. A seca e a crise hídrica de 2014-2015 em São Paulo. Revista USP, n. I06, p. 31-44, 2015.

MARTINS, V. O. Sistemas de Certificação Ambiental e Norma Brasileira de Desempenho. 2014. 22of. Dissertação (Mestrado em Ambiente Construído) - Universidade Federal de Juiz de Fora, Juiz de Fora, 2014.

MONTE, Helena Marecos do; ALBUQUERQUE, António. Reutilização de águas residuais. 2010.

RIGO, Michelle M. et al. Destinação e reuso na agricultura do lodo de esgoto derivado do tratamento de águas residuárias domésticas no Brasil. Gaia Scientia, v. 8, n. I, p. 174-I86, 2014.

RIGOTTI, Pedro Antonio Cardias. Projeto de aproveitamento de água condensada de sistema de condicionadores de ar. 2015 .

ROCHA, Felizardo Adenilson; SILVA, JO da; BARROS, Flávia Marianni. Reuso de águas residuárias na agricultura: a experiência israelense e brasileira. Enciclopédia Biosfera, v. 6, n. II, 2010.

RUPP, Ricardo Forgiariniet al. Conforto térmico humano em escritórios com sistema central de condicionamento artificial em clima subtropical úmido: estudos de campo vs. abordagem analítica. Ambiente Construído, v. 17, n. I, p. III-123, 2017.

SANTOS, Michelle Ludmila Guedes; ARAUJO, Elder Silva; Alexandria, ADRIANA Soraya Monteiro. Reaproveitamento da água do chuveiro e lavatório para reutilização na descarga do vaso sanitário. In: VII CONNEPI-Congresso Norte Nordeste de Pesquisa e Inovação. 2012.

SILVA, Carlos Henrique R. Tomé. Recursos hídricos e desenvolvimento sustentável no Brasil. 
2012.

SOUZA, Welder Boeno de. Comparação entre dois sistemas de ar-condicionado para um prédio histórico. 2010.

TORRES, Tattiana Lupion et al. Gestão do uso da água na indústria: aplicação do reúso e recuperação. Revista Gestão \& Sustentabilidade Ambiental, v. 7, n. 2, p. 370-385, 2018.

TUNDISI, José Galizia; MATSUMURA-TUNDISI, Takako. Recursos hídricos no século XXI. Oficina de Textos, 2011. 